\title{
Glaciological and oceanographic evidence of high melt rates beneath Pine Island Glacier, West Antarctica
}

\author{
Adrian Jenkins, ${ }^{1}$ David G. Vaughan, ${ }^{1}$ Stanley S. Jagobs, ${ }^{2}$ Hartmut H. Hellmer, ${ }^{2 *}$ John R. Keys ${ }^{3}$ \\ ${ }^{1}$ British Antarctic Survey, Natural Environment Research Council, Madingley Road, Cambridge CB3 OET, England \\ ${ }^{2}$ Lamont-Doherty Earth Observatory of Columbia University, Palisades, New York 10964, U.S.A. \\ ${ }^{3}$ Department of Conservation, Tongariro/Taupo Conservancy, Turanga Place, Turangi, New Zealand
}

\begin{abstract}
Satellite imagery indicates that the floating terminus of Pine Island Glacier has changed little in extent over the past two decades. Data on the velocity and thickness of the glacier reveal that calving of $28 \pm 4 \mathrm{Gta}^{-1}$ accounts for only half of the ice input near the grounding line. The apparently steady configuration implies that the remainder of the input is lost by basal melting at a mean rate of $12 \pm 3 \mathrm{~m} \mathrm{a}^{-1}$. Ocean circulation in Pine Island Bay transports $+1^{\circ} \mathrm{C}$ waters beneath the glacier and temperatures recorded in melt-laden outflows show that heat loss from the ocean is consistent with the requirements of the calculated melt rate. The combination of iceberg calving and basal melting lies at the lower end of estimates for the total accumulation over the catchment basin, drawing into question previous estimates of a significantly positive mass budget for this part of the ice sheet.
\end{abstract}

\section{INTRODUGTION}

Approximately $200000 \mathrm{~km}^{2}$ of West Antarctica are drained by Pine Island Glacier, which discharges via a short floating terminus into Pine Island Bay (Fig. 1). The catchment basin comprises most of Ellsworth Land and includes a region where the subglacial bed sinks to $2500 \mathrm{~m}$ below sea level. The glacier is about $30 \mathrm{~km}$ in width and about $200 \mathrm{~km}$ in length from the point where it first becomes discernible in satellite images as fast-moving ice separate from the surrounding ice sheet to the calving front. Figure 2 a shows a mosaic of four synthetic aperture radar (SAR) images of the glacier and surrounding area obtained in 1992.

Pine Island Glacier and its neighbour, Thwaites Glacier, have been highlighted as parts of the West Antarctic ice sheet that may be particularly vulnerable to climatic warming (Thomas and others, 1979; Hughes, 1981; Stuiver and others, 1981, Thomas, 1984). They are the largest outlet glaciers in West Antarctica not discharging into substantial ice shelves. In both cases the glacier bed deepens inland of the grounding line. Early theories on the dynamics of marine ice sheets suggested that such a situation is inherently unstable (Weertman, 1974; Thomas and Bentley, 1978), because inland migration of the grounding line would be selfperpetuating and irreversible without a substantial change in climatic forcing.

Despite the interest aroused by theoretical studies, reliable glaciological data on Pine Island Glacier have remained sparse. In 1981, an airborne radio-echo sounding survey (Crabtree and Doake, 1982) measured surface eleva-

\footnotetext{
* Present address: Alfred-Wegener-Institut für Polar- und Meeresforschung, Columbusstraße, D-27515 Bremerhaven, Germany.
}

tion and ice thickness, from which the extent of the floating ice was determined (Fig. 2a). This study placed the grounding line $85 \mathrm{~km}$ upstream of the 1981 ice front, though the absolute locations assigned to both grounding line and ice front were subject to errors in the navigation system used. Early analyses (Crabtree and Doake, 1982; Lindstrom and Hughes, 1984) suggested a large, positive mass budget for

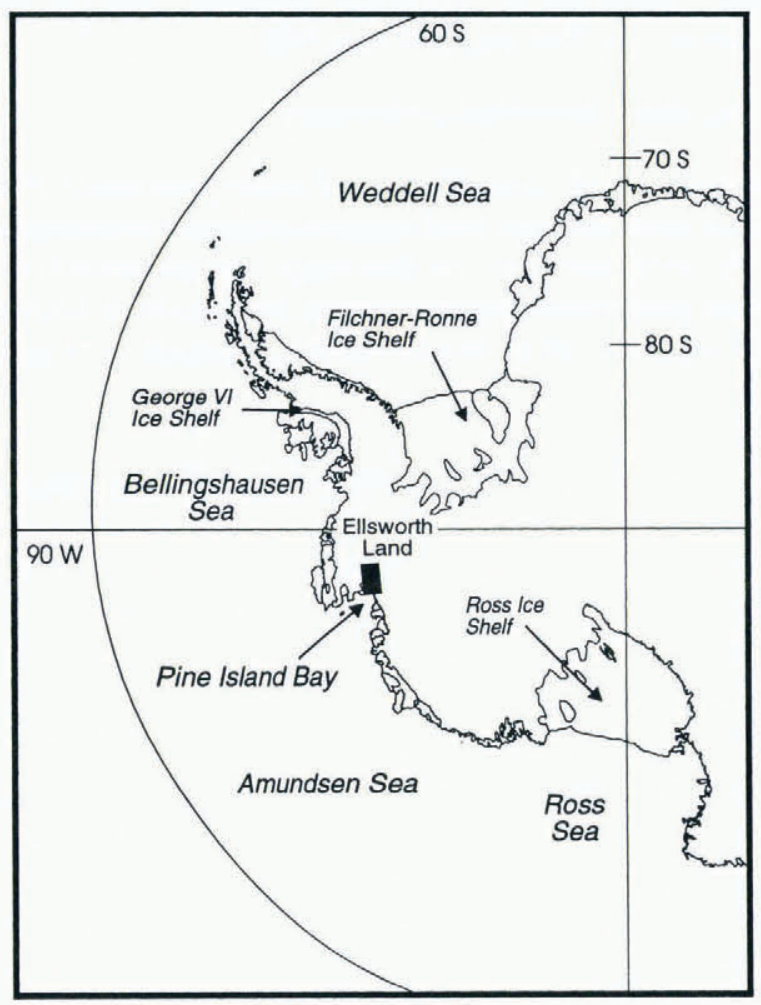

Fig. 1. Map of West Antarctica showing the location of Pine Island Bay. The solid black rectangle indicates the area covered by Figure 2. 

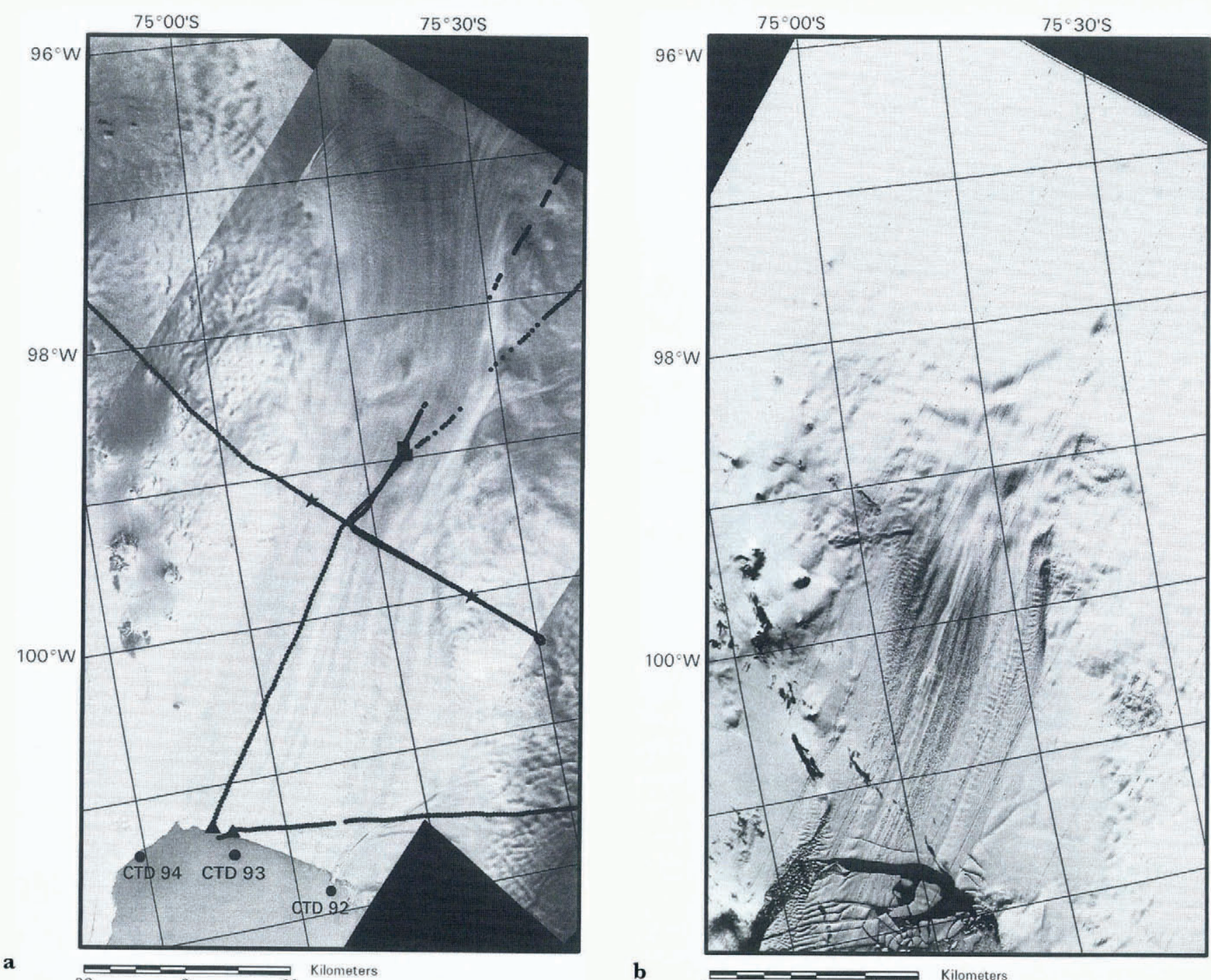

$\underset{020}{2}$ Kilometers

20

20

Fig. 2. (a) Mosaic of two ERS-1 SAR images (orbit 3174, frames 5193 and 5211) showing Pine Island Glacier on 4 December 1992. Two more images from 23 February 1992 (orbit 7521, frames 5607 and 5589) show some of the surrounding area. All images have been georeferenced using the scene corner coordinates supplied by ESA, accurate to $\sim 50 \mathrm{~m}$. Dotted lines indicate segments of continuous ice-thickness data obtained from a radio-echo sounding survey flown in February 1981. Locations of the ice front, the grounding line and the glacier margins, as inferred from the radio-echo data, are indicated by triangles, squares and asterisks, respectively. The discrepancy in the position of the margins provides an indication of the accuracy of the Doppler navigation records used to fix the flight lines. Numbered circles indicate the locations of conductivity-temperature-depth (CTD) profiles measured within $\sim 500 \mathrm{~m}$ of the ice front on 14 March 1994. The mass-balance calculations of section 3 concern the $70 \mathrm{~km}$ of the glacier lying between the northeast-southwest flight track near $99.5^{\circ} \mathrm{W}$ and the $1994 \mathrm{ice}$ front. (b) Landsat 1 scene of the same area acquired on 24 January 1973 (path 246, row 114).

the inland catchment basin but these conclusions have been brought into question by a more recent study (Lucchitta and others, 1995). The latter work is based on more reliable measurements of ice velocity, made possible by the advent of high-resolution SAR imagery and sophisticated featuretracking algorithms.

In this paper we use the available data on the floating part of Pine Island Glacier to estimate the rates of iceberg calving and basal melting. We are motivated by the results of a 1994 hydrographic survey of Pine Island Bay (Jacobs and others, 1996) showing sea-water temperatures more than $3^{\circ} \mathrm{C}$ above the freezing point near the glacier. Such warm waters are widespread on the continental shelves of the Amundsen and Bellingshausen Seas and have been implicated in supporting high melt rates reported elsewhere in this sector (Potter and Paren, 1985).

\section{RECENT BEHAVIOUR REVEALED BY SATELLITE IMAGERY}

Figure $2 \mathrm{~b}$ shows a 1973 Landsat image of the glacier. Positional control has been derived from the SAR image (Fig. 2a) by warping the Landsat scene until all fixed points overlay. The reliability of this process is compromised by the paucity of fixed points common to both images, and by the lateral displacement of topographic features in the SAR image, as a result of side-on illumination by the radar. Overall, we consider the relative positional accuracy to be good to $\pm 2 \mathrm{~km}$. A visual comparison of the images suggests a steady regime, with flowlines, crevasse patterns and topographic features appearing to have altered little over the two-decade time lapse between the acquisitions. The positions of the calving front are reproduced in Figure 3, along with those taken from a 1982 Landsat image and two more 


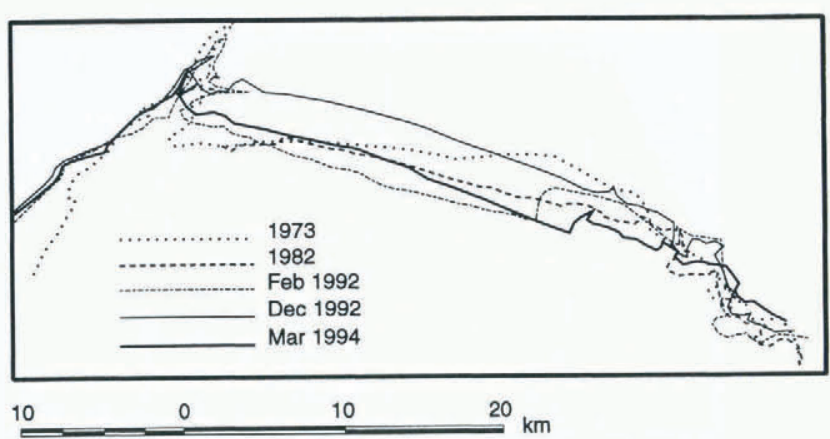

Fig. 3. Composite of ice-front locations taken from images acquired on 24 January 1973 (Landsat; Fig. 2b), 15 January 1982 (Landsat), 9 February 1992 (ERS-1 SAR), 4 December 1992 (ERS-1 SAR; Fig. 2a) and 15 March 1994 (ERS1SAR). Relative positions should be accurate to within $2 \mathrm{~km}$.

SAR images from the early 1990s. We conclude that, apart from the fluctuations associated with the quasi-periodic nature of iceberg calving, the ice front has maintained a stable position since the early 1970s.

Sediment cores collected in Pine Island Bay indicate that ice-shelf cover was more extensive as recently as 100 years ago and ongoing retreat of $\sim 0.8 \mathrm{~km} \mathrm{a}^{-1}$ is suggested by terminus locations recorded in 1966, 1973 and 1985 (Kellogg and Kellogg, 1987). The 1973 image (Fig. 2b) shows what is apparently the aftermath of a significant retreat of the ice front from a position that it has not since re-occupied. We cannot say whether this event was one stage in a continuing recession of the glacier or not. Our record of ice-front locations from the succeeding two decades (Fig. 3) indicates that the position recorded in 1985 was a transitory minimum but tells us nothing about longer-term changes. However, it is the behaviour of the floating section of Pine Island Glacier over the past few decades that is of primary concern to us.

From a sequence of ERS-1 SAR images taken in February 1992, December 1992 and March 1994, we estimate an ice velocity of $2.6 \mathrm{~km} \mathrm{a}^{-1}$ at the calving front. We have assumed that no calving took place between the times of the latter two images, so that the ice-front advance apparent in Fioure 3 can be directly related to the ice velocity. Between February and December 1992 the ice front retreated but the earlier of these images shows a prominent rift about $6 \mathrm{~km}$ upstream of the ice front (Lucchitta and others, 1995, fig. 5), which we have assumed is the site of calving. The two estimates of ice velocity provided by the three images are consistent. Three independent studies of a series of Landsat images acquired between 1973 and 1975 (Crabtree and Doake, 1982; Williams and others, 1982; Lindstrom and Tyler, 1984) put the velocity at the ice front between 2.1 and $2.4 \mathrm{~km} \mathrm{a}^{-1}$. Our calculation of $2.6 \mathrm{~km} \mathrm{a}^{-1}$ could indicate a small acceleration of the flow following the large calving event in the early 1970 s, but may simply reflect the better positional control on the newer images.

The observation that the floating terminus of Pine Island Glacier has changed little over recent years implies that current rates of input and output are approximately in balance. In the following section we use this fact to derive the basal melt rate from our knowledge of the other components of the mass budget. It is likely that such a state of balance almost always exists, because the residence time for ice within this small ice shelf is only a few decades. We stress that this implies nothing about the state of the glacier system as a whole, which has a response time to external forcing measured in millennia.

\section{COMPONENTS OF THE MASS BUDGET}

We calculate the upstream input, the calving flux and the surface mass balance directly from available data and infer the basal melt rate from the residual of these estimates. To derive the upstream input, we use a gate that lies $20 \mathrm{~km}$ downstream of the grounding line, where a flight line crosses the glacier (Fig. 2a). Calving is estimated from the flux through an output gate at the March 1994 ice front. For simplicity we define gates that are aligned perpendicular to the direction of ice flow, and where necessary extrapolate data up- and downstream from the sites of the original measurements to points lying on the gates. The input gate extends to the edges of the glacier, and flowlines originating from here define the downstream area of interest to us. From Figure 2 we estimate this area to be $2500 \pm 250 \mathrm{~km}^{2}$.

\subsection{Upstream input}

From the SAR image (Fig. 2a), we estimate that the width of the upstream gate is $31 \mathrm{~km}$. Lucchitta and others (1995) measured a velocity of $2.6 \mathrm{~km} \mathrm{a}^{-1}$ close to the centre line and we extrapolate to an assumed value of zero at the margins using a quartic equation (Fig. 4a). This is the theoretical velocity profile for an ice shelf of uniform cross-stream thickness in a parallel-sided bay, with a constant flow-law rate factor and a flow-law exponent of 3 (Budd, 1966). The ice-thickness profile (Fig. 4b) crosses the glacier at an angle of about $75^{\circ}$ to the flow and coincides with the gate only at the centre line. With little knowledge of the longitudinal thickness gradients, it is difficult to extrapolate these data. However, they all lie within $4 \mathrm{~km}$ of the gate and, with the assumed symmetry in the velocity profile, the total flux we calculate will be influenced only by cross-stream variations in the thickness gradient. In the absence of data, we simply make a linear adjustment of the distance scale shown in Figure $4 \mathrm{~b}$ to reduce the total width to $31 \mathrm{~km}$. Integrating the product of thickness and velocity across the input gate then gives a total volume flux of $61 \mathrm{~km}^{3} \mathrm{a}^{-1}$.

The ice-thickness measurements should be accurate to $\pm 2 \%$ but additional uncertainties have been introduced because they are not coincident with the gate. Assuming that cross-stream variations in the longitudinal thickness gradient are no more than \pm 0.01 , the mean value of the longitudinal profile of Crabtree and Doake (1982), then the additional errors should not exceed $\pm 40 \mathrm{~m}$. This gives an overall error of $\pm 5 \%$ in the thickness profile. Lucchitta and others (1995) considered their measurements of crevasse movement to be accurate to $\pm 50 \mathrm{~m}$, suggesting an error of $\pm 2.5 \%$ in the centre-line velocity, but our extrapolation to the margins is also subject to uncertainty. Using a cubic velocity profile, as found on the Amery Ice Shelf (Budd, 1966), instead of our quartic one, would reduce the inflow by $6 \%$. However, the high shear at the margins of Pine Island Glacier should soften the ice there, leading to a steeper velocity gradient through a narrower shear zone than that indicated in Figure 4a. Plug flow is an unrealistic extreme that would increase the flux by $22 \%$. Overall, we assume the velocities are accurate to $\pm 10 \%$. The error in the glacier width should be no more than $\pm 2 \%$. The cumulative error 


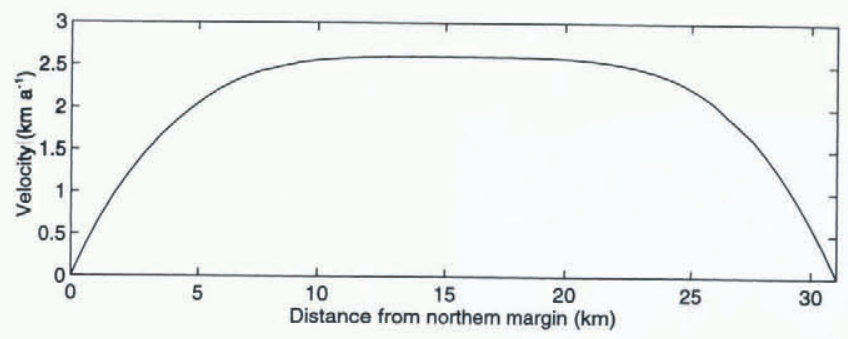

a

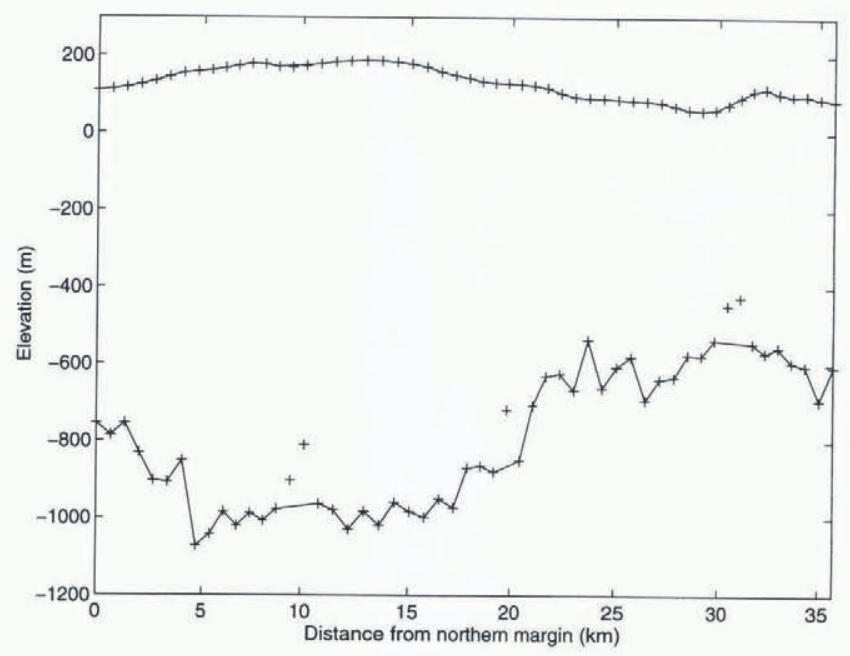

b

Fig. 4. (a) Transverse profile of velocity used to estimate ice flux through the input gate. A quartic equation, $v^{\prime}=1-$ $\left(2 x^{\prime}-1\right)^{4}$ where $v^{\prime}$ is velocity, scaled by the maximum value, and $x^{\prime}$ is distance, scaled by the total width, has been used to extrapolate from the measured centre-line value to an assumed value of zero at the margins. (b) Transverse section of surface and basal elevation across Pine Island Glacier about $20 \mathrm{~km}$ downstream of the grounding line (Fig. 2a). Crosses indicate points obtained by hand-digitization of the analogue records. Solid lines indicate profiles used in this study after editing points where diffraction hyperbolae rather than basal reflections were picked.

in the volume flux, taking all the aforementioned sources into consideration, is $\pm 11 \%$, or $\pm 7 \mathrm{~km}^{3} \mathrm{a}^{-1}$.

A mean ice density calculated from the data in Figure $4 \mathrm{~b}$ would be unreliable, because the only control on the absolute surface elevation of the glacier is the aircraft pressure altimeter, which cannot be expected to be particularly accurate for a long flight over unknown terrain. We would expect the air contained in the upper layers of firn to comprise around $10 \pm 5 \mathrm{~m}$ of the total thickness, suggesting a mean density of $907 \pm 5 \mathrm{~kg} \mathrm{~m}^{-3}$. The uncertainty makes a negligible contribution to the overall error budget. We arrive at a figure of $56 \pm 6 \mathrm{Gt} \mathrm{a}^{-1}\left(1 \mathrm{Gt}=10^{12} \mathrm{~kg}\right)$ for the mass input through the upstream gate.

\subsection{Ice-front discharge}

The output gate extends from the point where the ice front turns through about $125^{\circ}$, southward to the prominent flowline that can be seen $3 \mathrm{~km}$ to the east of CTD station 92 (Fig. 2a). The width of the gate measured perpendicular to the ice flow is $31 \mathrm{~km}$. We assume a flat cross-stream velocity profile, because the gate does not extend right into the shear mar- gins. For the velocity, we use the value of $2.6 \mathrm{~km} \mathrm{a}^{-1}$ determined from the SAR images (section 2).

The height of the glacier front in March 1994 was measured from RVIB Nathaniel B. Palmer using sextant angles and ship's radar ranges. To estimate the ice thickness from these data, we must assume that the ice front is vertical and floating in hydrostatic equilibrium. This is almost certainly not the case for two extreme heights, in excess of $80 \mathrm{~m}$, measured close to the margins, so we have excluded these two points from the analysis. The edited profile is shown in Figure 5 and has a mean height of $48 \mathrm{~m}$ across the output gate.

We have estimated the mean density of the ice column using the elevation and thickness data of Crabtree and Doake (1982) taken from the profile that crossed the glacier just upstream of the ice front (Fig. 2a). The short section of this flight that passed over the sea provides additional control on the absolute elevation of the aircraft. We compute an average density of $900 \mathrm{~kg} \mathrm{~m}^{-3}$, implying an air content of about $9 \mathrm{~m}$, which seems consistent with our estimate of the upstream density. Using a sea-water density of $1027.5 \mathrm{~kg} \mathrm{~m}^{-3}$ (Jacobs and others, 1996), the mean ice-front height of $48 \mathrm{~m}$ equates to a thickness of $390 \mathrm{~m}$. Combined with a width of $31 \mathrm{~km}$ and a velocity of $2.6 \mathrm{~km} \mathrm{a}^{-1}$, this gives a total flux of $28 \mathrm{Gt} \mathrm{a}^{-1}$ through the output gate.

The largest uncertainty in the calving flux originates from our use of the measured height of the ice front to derive the ice thickness. We must consider both the errors in the measurements themselves (about $\pm 5 \%$ ) and the fact that the height showing above the sea surface may be affected by peculiarities in shape beneath the water line. We suspect that differences in the shape of the ice front account for at least some of the variability apparent in Figure 5 and, as a result, we attach an uncertainty of $\pm 10 \%$ to the mean elevation of the glacier's upper surface. Our value for the mean density of the ice is probably good to $\pm 5 \mathrm{~kg} \mathrm{~m}^{-3}$, but this gives rise to errors of $\pm 4 \%$ in the density contrast between ice and sea water, and a cumulative error of $\pm 11 \%$ in the thickness. The measured displacement of the ice front is probably good to $\pm 100 \mathrm{~m}$ but, in converting this to a velocity, we must make the assumption that the overwhelming majority of the ice is lost by major calving events, like that in mid- 1992 (Lucchitta and others, 1995). Any small-scale attrition of the ice front that has gone undetected will lead to an underestimate of the velocity. Our straight-line extrapolation of the velocity to the margins must introduce a small error in the opposite sense, so that the overall error in the velocity probably does not exceed $\pm 250 \mathrm{~m} \mathrm{a}^{-1}$. We take the width of the output gate to be accurate to $\pm 1 \mathrm{~km}$. The cumulative error in the ice-front discharge estimated from all the aforementioned sources is $\pm 15 \%$ or $\pm 4 \mathrm{Gt} \mathrm{a}^{-1}$.

\subsection{Surface sublimation}

Kellogg and others (1985) retrieved firn samples from several unspecified locations on Pine Island Glacier. From observations of the sintering characteristics and a measured surface density of $650 \mathrm{~kg} \mathrm{~m}^{-3}$ they estimated a net surface loss of $0.67 \mathrm{~m} \mathrm{a}^{-1}$, primarily caused by sublimation. Assuming a mean density of $500 \mathrm{~kg} \mathrm{~m}^{-3}$ for the sublimated layers, a mass loss of $340 \mathrm{~kg} \mathrm{~m}^{-2} \mathrm{a}^{-1}$ is implied. However, this calculation is based on a comparison with firn characteristics observed at Siple Station, which lies in a region of high accumulation and low temperature. While precipitation rates and temperatures may be similar over much of the 


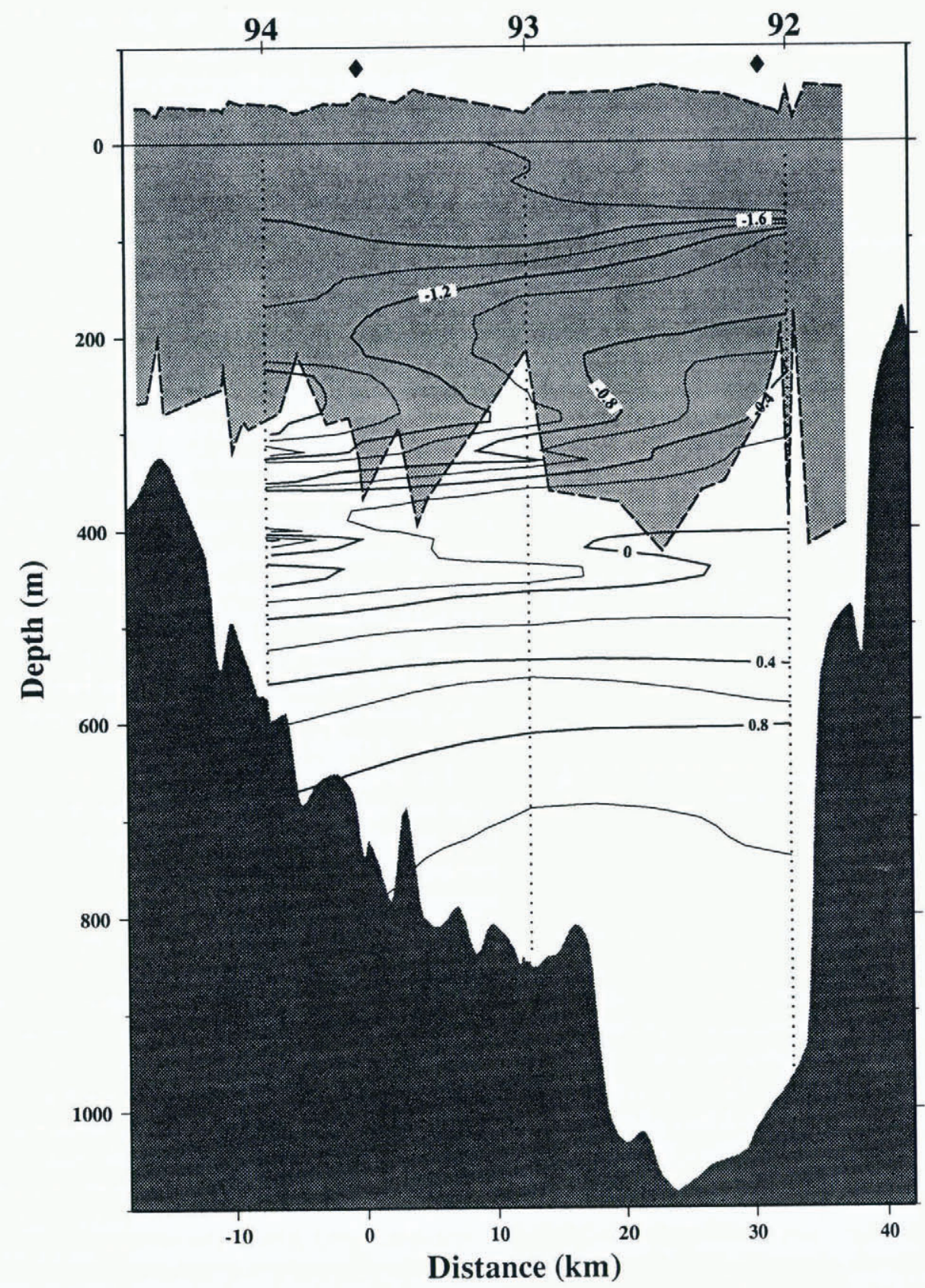

Fig. 5. Vertical section of potential temperature (in ${ }^{\circ} \mathrm{C}$ ) measured near the front of Pine Island Glacier on 14 March 1994. Station numbers are given at the top and corresponding locations are shown in Figure 2a. Heavy shading indicates the seabed; light shading, the glacier. Contemporaneous measurements of surface elevation (except two points indicated by diamonds above the glacier) have been used to estimate ice thickness, assuming that the glacier floats in hydrostatic equilibrium. The distance axis follows the ice front, which turns through $\sim 125^{\circ}$ at the origin. The output gate, which measures $31 \mathrm{~km}$ perpendicular to the flow direction, extends from the origin to $32.1 \mathrm{~km}$ on this scale.

Pine Island Glacier catchment, the transition to a zone of net surface loss as the ice front is approached must induce changes in the near-surface density profile. It seems unlikely that the sublimation rate on the glacier should greatly exceed the $200 \mathrm{~kg} \mathrm{~m}^{-2} \mathrm{a}^{-1}$ reported by Frezzotti (1993) for the blue-ice areas in Terra Nova Bay, where persistent, strong katabatic winds are well documented. A rate of $200 \pm 100 \mathrm{~kg} \mathrm{~m}^{-2} \mathrm{a}^{-1}$ probably covers the most likely range of values.

Applying the above sublimation rate to the entire $2500+250 \mathrm{~km}^{2}$ of Pine Island Glacier lying between the input and output gates gives a total mass loss of $0.5 \pm 0.25$ $\mathrm{Gt} \mathrm{a}^{-1}$. This is about $1 \%$ of the mass flux through the input gate, and falls well within the error bar of $\pm 6 \mathrm{Gt} \mathrm{a}^{-1}$ estimated for the input.

\subsection{Basal melting}

The preceding calculations indicate that iceberg calving and surface sublimation account for only half of the mass flowing through the input gate near the grounding line of Pine Island Glacier. If the budget of the floating part of the glacier is currently balanced, $28 \pm 7 \mathrm{Gt} \mathrm{a}^{-1}$ must melt from the $2500 \pm 250 \mathrm{~km}^{2}$ of the glacier base lying in the study area. Assuming a density of $917 \mathrm{~kg} \mathrm{~m}^{-3}$ for ice at the base of the glacier implies a mean melt rate of $12 \pm 3 \mathrm{~m} \mathrm{a}^{-1}$.

Localized melt rates of up to $8 \mathrm{~m} \mathrm{a}^{-1}$ have previously been reported for George VI Ice Shelf (Bishop and Walton, 
1981) but there is considerable spatial variability and the average lies close to $2 \mathrm{~m} \mathrm{a}^{-1}$ (Potter and Paren, 1985). Beneath the larger Antarctic ice shelves, generally lower melt rates and regional freezing lead to averages of less than $1 \mathrm{ma}^{-1}$ (Jacobs and others, 1992). The waters of Pine Island Bay must provide a significant source of heat to sustain the high melt rate we have calculated beneath the glacier.

\section{OCEANOGRAPHY OF PINE ISLAND BAY}

In March 1994, a hydrographic survey was conducted in Pine Island Bay from RVIB Nathaniel B. Palmer. Three conductivity-temperature-depth (CTD) stations were occupied near the calving front of Pine Island Glacier (Fig. 2a). Accompanying sea-floor depth soundings revealed a trough carved into the continental shelf, reaching a depth of $1080 \mathrm{~m}$ close to the steep southern flank. A water mass identified as almost undiluted Circumpolar Deep Water (CDW), with potential temperature and salinity values above $1{ }^{\circ} \mathrm{C}$ and $34.68 \%$, respectively, filled the trough at depths greater than $800 \mathrm{~m}$ (Fig. 5). Above this level, the water column is influenced to varying degrees by meltwater emerging from the cavity beneath the glacier. At station 92 the characteristics of the entire water column between 100 and $800 \mathrm{~m}$ can be attributed to a mixture of CDW and meltwater (Jacobs and others, 1996), while at the other two stations the meltwater influence can be identified only in distinct layers with relatively homogeneous properties. The interleaving of these layers with the ambient water column gives rise to the temperature inversions visible between 200 and $500 \mathrm{~m}$ depth on these more northerly stations. All the outflows have potential temperatures well above the in situ freezing point, indicating that not all the available heat has been used for melting.

To calculate the net transport of meltwater across our hydrographic section, we use a simple box model, which assumes inflow for the homogeneous bottom layer, $\sim 300 \mathrm{~m}$ thick, and outflow for the remaining water column up to the average ice-front draft of $340 \mathrm{~m}$. The inflow box is constrained by the bottom topography to lie between the southern and the central station. We constrain the outflow box similarly, because of the predominance of the meltwater signature in the south. From density differences between stations 92 and 93, Jacobs and others (1996) calculated a geostrophic transport through the outflow box of $0.172 \mathrm{~Sv}$ $\left(1 \mathrm{SV}=10^{6} \mathrm{~m}^{3} \mathrm{~s}^{-1}\right)$. A net cooling of $0.51^{\circ} \mathrm{C}$ can be derived from the difference in the mean potential temperature below $800 \mathrm{~m}$ and that between 340 and $800 \mathrm{~m}$ at station 92 . Conservation of mass and energy give the following:

$$
\begin{aligned}
Q_{\text {out }} & =Q_{\text {in }}+M \\
Q_{\text {out }} c \Theta_{\text {out }} & =Q_{\text {in }} c \Theta_{\text {in }}+M c \Theta_{\mathrm{f}}-M L_{\mathrm{i}}-M c_{\mathrm{i}}\left(\Theta_{\mathrm{f}}-\Theta_{\mathrm{i}}\right)
\end{aligned}
$$

where $Q$ represents a mass of sea water, $M$ a mass of meltwater, $\Theta$ a potential temperature, $c$ a specific heat capacity and $L$ a latent heat of fusion. Subscripts "in" and "out" are self-explanatory, subscript "i" indicates ice properties and subscript "f" indicates the freezing point of sea water. The first three terms in the second equation, reading from left to right, represent the heat fluxes associated with the outflow, the inflow and the meltwater, respectively. The fourth term represents the latent heat given up by the ocean to melt the ice and the final term is the heat lost by conduction into the ice. By combining the above two equations, we can express the mass of meltwater as:

$$
M=\frac{Q_{\text {out }} c\left(\Theta_{\text {in }}-\Theta_{\text {out }}\right)}{c\left(\Theta_{\text {in }}-\Theta_{\mathrm{f}}\right)+L+c_{\mathrm{i}}\left(\Theta_{\mathrm{f}}-\Theta_{\mathrm{i}}\right)} .
$$

We take values of $3.34 \times 10^{5} \mathrm{~J} \mathrm{~kg}^{-1}$ for the latent heat of fusion and $2 \times 10^{3}$ and $4 \times 10^{3} \mathrm{~J} \mathrm{~kg}^{-1} \mathrm{~K}^{-1}$ for the specific heat capacities of ice and sea water, respectively. The freezing point at the mean depth of the glacier base is $-2.5^{\circ} \mathrm{C}$. Taking an inflow temperature of $1{ }^{\circ} \mathrm{C}$ and an ice temperature of $-20^{\circ} \mathrm{C}$, derived from the gradient of station 92 data on a plot of potential temperature vs salinity (Hellmer and others, in press), gives a meltwater flux of $30 \mathrm{Gt} \mathrm{a}^{-1}$.

Our assumption of geostrophic balance is questionable so close to boundaries and the meltwater in the outflow could have been gathered over the entire basal area of the floating ice, not just the $2500 \mathrm{~km}^{2}$ discussed in the previous section. While the use of station 92 data for the entire outflow maximizes the flux calculated by this method, there is certainly some meltwater influence in the northern CTD profile and at depths shallower than the ice-front draft, which we have excluded, and the most concentrated part of the outflow may pass to the south of station 92 . The above arguments suggest a large uncertainty in the meltwater flux calculated in this section but the result of the calculation is consistent with the glaciological mass balance and indicates that the ocean does have the capacity to sustain a high melt rate at the base of Pine Island Glacier.

\section{MASS BUDGET OF THE DRAINAGE BASIN}

Our analysis of the upstream input indicates that the mass flux across the grounding line of Pine Island Glacier is at least $56 \pm 6 \mathrm{Gta}^{-1}$. The true discharge is probably higher, as this figure does not take into account ice that melts from the base between the grounding line and the upstream gate. The two flotation points identified by Crabtree and Doake (1982) (Fig. 2a) give little information about the shape of the grounding line, but assuming it is a straight line perpendicular to the flow direction gives an additional $500 \mathrm{~km}^{2}$ of floating ice. To balance melting of $12 \mathrm{~m} \mathrm{a}^{-1}$ over this area, a further $5.5 \mathrm{Gt} \mathrm{a}^{-1}$ of ice would have to cross the grounding line. This probably represents an upper limit, because the topography apparent in Figure 2 is suggestive of a complex grounding zone with a number of pinning points and because the melt rate in this region is most likely smaller than the downstream average (Hellmer and others, in press). A figure of $4 \pm 2 \mathrm{Gt} \mathrm{a}^{-1}$ probably covers the most likely range of values for the ice flux that does not reach the input gate.

Our estimate for the total discharge from the inland basin becomes $60 \pm 6 \mathrm{Gt} \mathrm{a}^{-1}$. This lies at the lower extreme of estimates for the total accumulation in the Pine Island Glacier catchment, which range from 66 to $86 \pm 30 \mathrm{Gt} \mathrm{a}^{-1}$ (Crabtree and Doake, 1982; Lindstrom and Hughes, 1984). Given the large uncertainty in the accumulation, it is hard to argue that the net mass balance differs significantly from zero. Early suggestions of a large, positive mass budget (Crabtree and Doake, 1982; Lindstrom and Hughes, 1984) were based on underestimates of ice velocity at the grounding line. The work of Lucchitta and others (1995) effectively transferred the bulk of this imbalance across the grounding line, while our observations have dissipated it in the ocean.

The mass budget of the grounded parts of the Antarctic ice sheet influences global eustatic sea level. A recent review 
of data on ice accumulation and discharge for the major catchment basins (Bentley and Giovinetto, 1991) concluded that the ice sheet overall is growing at a rate of $40-400$ $\mathrm{Gt} \mathrm{a}^{-1}$, equivalent to a sea-level lowering of $0.1-1.1 \mathrm{~mm} \mathrm{a}^{-1}$. One of the largest contributions to this result is a $50 \mathrm{Gta}^{-1}$ positive budget assigned to Pine Island Glacier. If we take this basin to be in balance and redo the calculation of Bentley and Giovinetto (1991), we obtain upper and lower bounds of 230 and $-10 \mathrm{Gta}^{-1}$ on the excess input over the entire ice sheet. This suggests that further work is necessary before even the sign of Antarctica's contribution to sea-level change can be determined with confidence.

\section{SUMMARY AND CONCLUSIONS}

Recent data obtained from satellite imagery of Pine Island Glacier have revealed an apparent steadiness in the size and dynamics of the floating terminus. A calving flux of $28 \pm 4 \mathrm{Gt} \mathrm{a}^{-1}$ removes only about half of the mass flowing across the grounding line. Oceanographic observations in Pine Island Bay are consistent with melting of $12 \pm 3 \mathrm{~m} \mathrm{a}^{-1}$ over a basal area of $\sim 3000 \mathrm{~km}^{2}$ balancing the current mass budget. If a gradual retreat of the glacier is in progress, as suggested by records of ice-front location over the period 1966-85 (Kellogg and Kellogg, 1987), our values for calving and melting are most likely underestimates. These results are especially significant because Pine Island Glacier has often been regarded as the archetype of a fast-flowing, fastcalving fjord glacier, like some in Greenland, where melting of the floating terminus is assumed to be an insignificant component in the mass budget. Taking the high melt rate into account entails significant revisions to earlier estimates of Antarctica's mass balance (Bentley and Giovinetto, 1991; Jacobs and others, 1996).

The melt rate beneath Pine Island Glacier is 6 times higher than the mean value reported by Potter and Paren (1985) for George VI Ice Shelf, despite similar temperatures in the adjacent water column. The difference is most likely a result of the deep draft and steeply inclined base of the glacier. The deepest parts of George VI Ice Shelf are less than $500 \mathrm{~m}$ below sea level (Talbot, 1988), so are less exposed to inflowing CDW than the base of Pine Island Glacier, which reaches a depth of $1300 \mathrm{~m}$. The basal slope of the glacier averages $\sim 0.01$, compared with $\sim 0.001$ over much of George VI Ice Shelf, and the greater slope imparts a stronger gravitational forcing on the thermohaline circulation. The melt-laden outflows in Pine Island Bay, like those near George VI Ice Shelf (Potter and others, 1988), are significantly above the freezing point.

Of the thinning that occurs over the final $70 \mathrm{~km}$ of Pine Island Glacier, only one-third can be attributed to vertical strain. The remaining two-thirds, representing a thickness change of about $360 \mathrm{~m}$, is due to melting. The seabed beneath the glacier shoals by about $200 \mathrm{~m}$ between the grounding line and the ice front (Crabtree and Doake, 1982) and the continental shelf to the north and west has rugged topography with many potential pinning points for a more extensive ice shelf or a more advanced grounding line. If CDW were somehow excluded from Pine Island Bay, basal melting could fall by a factor of 50 (Hellmer and others, in press) and floating parts of the glacier would soon run aground. An advance of the calving front only $80 \mathrm{~km}$ beyond its March 1994 location would be sufficient for it to merge with the discharge from Thwaites Glacier, producing a more extensive ice shelf. The warmth of the ocean waters may play a similar role in limiting the ice cover throughout the Amundsen and Bellingshausen Seas. The present-day configuration of the Antarctic ice sheet has then, to some extent, been determined by the water masses invading the continental shelves exposed by Holocene retreat of its margins.

In the Ross and Weddell Seas, waters that are colder and denser than CDW form over the continental shelves as a result of haline convection beneath growing sea ice. Undiluted CDW does not penetrate beyond the continental-shelf break and the waters that interact with the ice shelves have temperatures close to the surface freezing point. Net melting of less than $1 \mathrm{~m} \mathrm{a}^{-1}$, regions of basal freezing and the formation of potentially supercooled Ice Shelf Water are the results. Although the continental shelves of the Amundsen and Bellingshausen Seas are of similar depth and extent to those of the Ross and Weddell Seas, dense shelf waters are absent. The difference has been attributed by Talbot (1988) to low surface salinities in the Amundsen and Bellingshausen Seas, resulting from high regional air temperatures and precipitation, a low net transport of sea ice off the shelf and a large input of meltwater from the ice sheet. Although the environments of the Ross and Filchner-Ronne Ice Shelves are often seen as the norm, they are the product of specific climatic conditions prevailing over broad, southerly continental shelves, which may only occur during Antarctic interglacials. During glacial maxima, ice shelves fringing an ice sheet that occupied all or most of the continental shelf would more likely see a deep water column analogous to the current conditions in Pine Island Bay. We might therefore speculate that any ice shelves fringing the ice sheets of the Last Glacial Maximum would be more likely to resemble those of the Amundsen and Bellingshausen Seas than those of the Ross andWeddell Seas. That is, they would most likely be small features extending $\sim 10-100 \mathrm{~km}$ from grounding line to ice front and experiencing basal melting of $\sim 1-10 \mathrm{~m} \mathrm{a}^{-1}$ with little, if any, basal freezing.

\section{ACKNOWLEDGEMENTS}

We are indebted to the captain and crew of RVIB Nathaniel B. Palmer and to all participants in cruise NBP94-02 to the Amundsen and Bellingshausen Seas. C. Giulivi processed the CTD data and S. Peng prepared Figure 5. The assistance of M. Siegert in copying the original radio-echo film is gratefully acknowledged. This paper was written while A. Jenkins was a visiting scientist at Lamont-Doherty Earth Observatory (contribution No. 5533), supported by U.S. Department of Energy grant DE-FG02-93-ER61716. The cruise was supported by the U.S. National Science Foundation (NSF/OPP 92-20009).

\section{REFERENGES}

Bentley, C. R. and M. B. Giovinetto. 1991. Mass balance of Antarctica and sea level change. In Weller, G., C. L. Wilson and B. A. B. Severin, eds. International Conference on the Role of the Polar Regions in Global Change: proceedings of a conference held June 11-15, 1990 at the University of Alaska Fairbanks. Vol. II. Fairbanks, AK, University of Alaska. Geophysical Institute/Center for Global Change and Arctic System Research, 481488.

Bishop, J. F. and J. L. W. Walton. 1981. Bottom melting under George VI Ice Shelf, Antarctica. f. Glaciol., 27(97), 429-447. 
Budd, W. 1966. The dynamics of the Amery Ice Shelf. F. Glaciol., 6 45), 335 358.

Crabtree, R. D. and C. S. M. Doake. 1982. Pine Island Glacier and its drainage basin: results from radio-echo sounding. Ann. Glaciol., 3, 65-70.

Hellmer, H. H., S. S. Jacobs and A. Jenkins. In press. Ocean erosion of a fast-moving Antarctic glacier in the Amundsen Sea. Deep Sea Res.

Hughes, T.J. 1981. Correspondence. The weak underbelly of the West Antarctic ice sheet. 7. Glaciol., 27 (97), 518-525.

Jacobs, S. S., H. H. Hellmer, C. S. M. Doake, A. Jenkins and R. M. Frolich, 1992. Melting of ice shelves and the mass balance of Antarctica. 7. Glaciol., $38(130), 375-387$.

Jacobs, S. S., H. H. Hellmer and A. Jenkins. 1996. Antarctic ice sheet melting in the southeast Pacific. Geophys. Res. Lett., 23 (9), 957-960.

Kellogg, T. B. and D. E. Kellogg. 1987. Recent glacial history and rapid ice stream retreat in the Amundsen Sea. 7. Geophys. Res., 92(B9), 88598864.

Kellogg, T. B., D. E. Kellogg and T. J. Hughes. 1985. Amundsen Sea sediment coring. Antarct. J. U.S., 20 (5), $79-81$.

Lindstrom, D. and T. J. Hughes. 1984. Downdraw of the Pine Island Bay drainage basins of the West Antarctic ice sheet. Antarct. f. U.S., 19(5), 56-58.

Lindstrom, D. and D. Tyler. 1984. Preliminary results of Pine Island and Thwaites glaciers study. Antart. f. U.S., 19(5), 53-55.

Lucchitta, B. K., C. E. Rosanova and K. F. Mullins. 1995. Velocities of Pine Island Glacier, West Antarctica, from ERS-1 SAR images. Ann. Glaciol., 21, 277-283.

Potter, J. R. and J. G. Paren. 1985. Interaction between ice shelf and ocean in
George VI Sound, Antarctica. In Jacobs, S.S., ed. Oceanology of the Antartic continental shelf. Washington, DC, American Geophysical Union, 35-58. (Antarctic Research Series 43.)

Potter, J. R., M. H. Talbot and J. G. Paren. 1988. Oceanic regimes at the ice fronts of George VI Sound, Antarctic Peninsula. Continental Shelf Res., 8(4), 347-362.

Stuiver, M., G. H. Denton, T.J. Hughes and J. L. Fastook. 1981. History of the marine ice sheet in West Antarctica during the last glaciation: a working hypothesis. In Denton, G. H. and T. J. Hughes, eds. The last great ice sheets. New York, etc., John Wiley and Sons, $319-436$.

Talbot, M. H. 1988. Oceanic environment of George VI Ice Shelf, Antarctic Peninsula. Ann. Glaciol., 11, 161-164.

Thomas, R. H. 1984. Ice sheet margins and ice shelves. In Hansen, J. E. and T. Takahashi, eds. Climate processes and climate sensitivity. Washington, DC, American Geophysical Union, 265-274. (Geophysical Monograph 29, Maurice Ewing Series 5.)

Thomas, R. H. and C. R. Bentley. 1978. A model for Holocene retreat of the West Antarctic ice sheet. Quat. Res., 10(2), 150-170.

Thomas, R. H., T.J. O. Sanderson and K. E. Rose. 1979. Effect of climatic warming on the West Antarctic ice sheet. Nature, 277 (5695), 355-358.

Weertman, J. 1974. Stability of the junction of an ice sheet and an ice shelf. 7 . Glaciol., $13(67), 3-11$

Williams, R. S., Jr, J. G. Ferrigno, T. M. Kent and J. W. Schoonmaker, Jr. 1982. Landsat images and mosaics of Antarctica for mapping and glaciological studies. Ann. Glaciol., 3, 321-326.

MS received 17 June 1996 and accepted in revised form 3 September 1996 